\title{
Amistad, hiperconexión y educación: un análisis conceptual a partir de Aristóteles
}

\author{
Alberto Sánchez-Rojo ${ }^{1}$ \\ ORCID: 0000-0003-2532-5867 \\ Josu Ahedo-Ruiz² \\ ORCID: 0000-0002-2480-5423
}

\section{Resumen}

Hoy en día habitamos un mundo de conexión permanente donde nuestra atención es constantemente reclamada de manera simultánea por múltiples frentes. Esto nos conduce a relaciones de amistad meramente superficiales. A través de un detallado análisis conceptual, este artículo muestra hasta qué punto esto es cierto y en qué medida merece la pena, desde un punto de vista educativo, que los jóvenes aprendan a vivir sus relaciones de amistad con algo más de profundidad. Para ello, primeramente, se recurre al actualmente olvidado concepto aristotélico de amistad perfecta. Se trataba de un tipo de amistad profunda y esencial que Aristóteles distinguía de otros tipos más superficiales y accidentales. En segundo lugar, se analiza profusamente el estado de cosas actual. A través de varios estudios tanto teóricos como empíricos se demuestra que hoy en día carecemos del tiempo suficiente del que sería necesario disponer a fin de construir vínculos de amistad profundos y no superficiales. En tercer lugar, señalamos la manera en la que el campo educativo ha sido influido por la inercia del contexto. Esto ha llevado a que la escuela y también las familias sólo potencien amistades superficiales. Finalmente, se concluye que la amistad perfecta está directamente relacionada con la moral. De esta forma, si queremos que las futuras generaciones crezcan como sujetos morales, es importante dotarles del tiempo necesario para que cultiven amistades perfectas.

\section{Palabras clave}

Filosofía de la educación - Sociedad del conocimiento - Aristóteles - Amistad.

1- Universidad Complutense de Madrid, Madrid, España. Contacto: asanchezrojo@ucm.es.

2- Universidad Internacional de La Rioja, La Rioja, España. Contacto: josu.ahedo@unir.net. 


\title{
Friendship, hyperconnectivity, and education: a conceptual analysis from Aristotle
}

\begin{abstract}
Nowadays we dwell in a permanently connected world in which our attention is constantly and simultaneously claimed by multiple fronts. This leads us to merely superficial relationships. Through a detailed conceptual analysis, this paper shows to what extent this is true and how much it is worth for young people, and from an educational standpoint, to learn how to live their relationships in greater depth. Therefore, and first of all, we turn to the currently forgotten Aristotelian concept of the perfect friendship. It was a kind of deep and essential friendship that Aristotle distinguished from other superficial and incidental types. Secondly, we profusely analyze the current state of affairs. Through several studies, both theoretical and empirical, we try and demonstrate that nowadays there time is scarce that one would need to have in order to develop deep and non-superficial friendship bonds. Thirdly, we point out the way the educational field has been influenced by this inertia context. This has led schools and families as well to only brace superficial friendships. Finally, we conclude that perfect friendship is directly connected with ethics. Then, if we want future generations to grow up as ethical individuals, it is important to provide them with sufficient time to cultivate perfect friendships.
\end{abstract}

\section{Keywords}

Philosophy of education - Knowledge society - Aristotle - Friendship.

Meus amigos/Quando me dão a mão/Sempre deixam/Outra coisa
Presença/OIhar/Lembrança/Calor
Meus amigos/Quando me dão a mão/Deixam na minha/A sua mão

PAULO LEMINSKI. Amizade.

\section{Introducción}

En noviembre de 1909 aparecía por primera vez publicado, en la revista inglesa The Oxford and Cambridge Review, un relato corto que llevaba por título The machine stops. En numerosas ocasiones considerado visionario, este relato, escrito por Edward Morgan Forster, cuenta la historia de un mundo futuro en que la gente vive bajo tierra, de manera aislada, en cuartos individuales y con una vida regida por un sistema tecnológico avanzado al que denominan la Máquina (the Machine). Este sistema hace de intermediario en toda relación que cada ser humano tiene, ya sea con el mundo o con otros seres humanos. Como en la mayoría de escritos del género de ciencia ficción, alguien pretende 
desafiar un sistema establecido que se muestra opresor y que terminará parando, de ahí el título del relato. No obstante, esto no nos interesa tanto, como el modo de vida que llevan las personas de este mundo imaginario ideado por Forster, el cual en parte podría ser comparado con nuestro mundo tecnológico e interconectado actual. En un momento determinado del texto, uno de sus principales protagonistas afirma lo siguiente:

Nosotros creamos a la Máquina para que cumpliese con nuestra voluntad, pero ahora no podemos conseguir que lo haga. Ella nos ha robado el sentido del espacio y el sentido del contacto, ha nublado toda relación humana y ha reducido el amor a un acto carnal, ha paralizado nuestros cuerpos y nuestras voluntades, y ahora nos compele a idolatrarla. (FORSTER, 2011, p. 33).

Si bien el relato de Forster es quizá excesivamente distópico, podemos reconocerle el acierto de señalar determinados hechos que, trasladados a nuestros días, invitan a la reflexión. No deja de resultar esencial, sobre todo desde un punto de vista educativo, pensar en qué medida hoy nuestras relaciones con el mundo y con los otros se han visto modificadas gracias a la red, si ha sido para mejor o para peor, si internet nos ha robado el sentido del espacio y de lo que tradicionalmente entendíamos por contacto humano, tal y como les pasó a los habitantes del relato de Forster, o, por el contrario, nada profundo o esencial ha cambiado. Si adoramos a internet y al mundo virtual, como si de divinidades se tratasen, o si siguen siendo meras herramientas que facilitan la vida humana.

Todas estas preguntas urgen ser contestadas y, de hecho, hace ya algunos años que contamos con expertos de las más diversas disciplinas que tratan de hacerlo. Existen múltiples estudios que reflejan, ya sea en sentido positivo o negativo, las potencialidades de un mundo tecnológicamente interconectado como el nuestro. Ahora bien, la gran mayoría de ellos, siguiendo diferentes metodologías, se dedican a hacer un análisis empírico de la realidad, siendo pocos los que se centran, no de manera secundaria sino fundamental, en un exhaustivo análisis conceptual que detecte posibles discrepancias a la hora de entender un concepto, así como las consecuencias que pueden derivarse de ello. Tal y como mostró Ong (1982), las tecnologías de la comunicación influyen claramente en la manera que tenemos de relacionarnos con otros, así como en el modo en que pasamos a entender dichas relaciones y los conceptos que les dan nombre. Sucedió con la aparición del lenguaje oral, con la escritura, con los medios de comunicación de masas y ahora la historia se repite con el ciberespacio y los medios tecnológicos que nos permiten acceder a él. Si bien no es común en nuestros días hacerlo, atender a estos cambios conceptuales resulta pedagógicamente esencial, pues nos permite legitimar desde un punto de vista normativo, el camino educativo que consideramos más adecuado tomar ante cambios cuya proyección en el futuro pueden directamente afectar a la manera en la que sea entendida la humanidad, así como su dignidad en cuanto tal.

Este artículo, situándose en esta línea, se propone realizar un detallado análisis del concepto de amistad, experiencia educativamente fundamental en la niñez, pero sobre todo en la adolescencia (MALLET, 2016). Dicho análisis nos permitirá determinar, desde un punto de vista pedagógico, cuál habrá de ser en nuestro contexto actual el modo ideal de educar a las nuevas generaciones tanto en su comprensión como en su ejercicio. 
Walker, Curren y Jones (2016) distinguen entre una definición filosófica de la amistad, relacionada con la virtud, frente a una concepción más psicológica, relacionada con el sentimiento. No hay duda de que el afecto está presente en la amistad, pero para los clásicos no era lo esencial de la relación. Para los clásicos, la amistad consistía en el "[...] hábito de querer amistosamente a quien se debe, como se debe y cuando se debe" (ZAGAL, 2014, p. 142), siendo necesario todo un proceso de formación a fin de poder llegar a ello. Esta concepción de la amistad como virtud es el primer punto de la teoría aristotélica en torno a la misma, la cual, tal y como trataremos de mostrar, hemos hoy perdido en pos de una perspectiva más emocional.

A fin de realizar de manera organizada y coherente el estudio detallado del concepto de amistad, este trabajo se divide en tres partes. En la primera de ellas se realiza un análisis de ciertos planteamientos aristotélicos que nos ayudarán a establecer cómo se ha venido entendiendo tradicionalmente la amistad en Occidente, ya que es un hecho que la influencia de Aristóteles a este respecto fue determinante (ORTEGA, 2002). Ahora bien, este artículo no hará un estudio pormenorizado de la teoría de la amistad aristotélica, tan sumamente compleja que incluso, tal y como muestra Berti (2001), encierra ciertas contradicciones. Tampoco atenderá al contexto histórico de Aristóteles, lo cual no implica, sin embargo, que vayamos a extrapolar anacrónicamente a nuestros días ideas que fueron expuestas en una realidad completamente diferente a la nuestra. Se trata más bien, siguiendo el proceder de autores como Hannah Arendt, de “[...] apoyar[nos] en tales configuraciones históricas con el objeto de purificar nuestra forma de encarar el presente y los conceptos con los que lo pensamos" (ARENDT apud BÁRCENA, 2006, p. 62).

La segunda parte del artículo se centra en analizar nuestro mundo actual, mostrando hasta qué punto un estado de constante conexión parece marcar de modo aparentemente inevitable una única manera de entender la amistad. Esto nos llevará al tercer apartado, donde se muestra hasta qué punto experimentar este modo de entender la amistad nos conduce, dentro del terreno pedagógico, a fomentarla como la única posible. Ahora bien, Aristóteles muestra la existencia de más de un tipo de amistad. Reduciendo nuestra experiencia a uno sólo estamos olvidando los demás y precisamente el que está desapareciendo es aquel que permitía teñir las relaciones humanas de moral. Teniendo esto en cuenta y atendiendo al carácter moral que debe acompañar a toda educación (BARRI0, 2007), concluiremos reclamando su recuperación, así como apuntando hacia ciertas vías que podrían ayudarnos a lograrlo.

\section{El concepto aristotélico de amistad}

El hecho de que para Aristóteles fuese tan importante analizar el concepto de

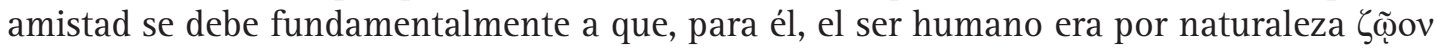
$\pi$ o $\lambda$ ítıкov, animal político; o, lo que es lo mismo, un ser cuya naturaleza consistía en no estar solo, sino más bien en desarrollar su vida en comunidad, compartiéndola con otros más allá del contexto familiar. Es por ello que, para él, "[...] la ciudad [era] anterior a la casa y a cada uno de nosotros" (ARISTÓTELES, 1983, p. 1253a), pues si bien el proceso de construcción de la ciudad dependía, primero de la unión de individuos particulares, y 
segundo de la unión de casas, ni los unos ni los otros podían ser tildados de humanos si el resultado final no era la ciudad, un espacio donde las relaciones que se daban no eran de parentesco, sino de amistad. Ahora bien, el que la naturaleza implicase una tendencia, no significaba que ésta no pudiese contrariarse; de hecho, por un lado, uno podía hacer un uso fraudulento de las relaciones, pensando en sí mismo no como parte de un todo, sino como ser singular que apenas busca el beneficio personal; y, por otro lado, era también posible no relacionarse y experimentar un aislamiento total. Conocer qué era la amistad y cómo podía construirse, ayudaba a evitar que estas dos circunstancias contrarias a la naturaleza humana pudiesen tener lugar.

De esta forma, Aristóteles dedica los libros VIII y IX de su Ética a Nicómaco a la amistad, señalando que tener amigos es el mayor bien externo porque nadie es feliz sin amigos. La amistad es para él "[...] una virtud o va acompañada de una virtud" (ARISTÓTELES, 2002, p. 1155a), habiendo sido ésta anteriormente definida como aquel "[...] hábito selectivo que consiste en un término medio relativo a nosotros, determinado por la razón y por aquella por la cual decidiría el hombre prudente" (p. 1107a), sujeto moral por excelencia, de acuerdo con su pensamiento. De esta forma, la virtud consistiría en un hábito que viene determinado por la razón, la cual, adecuándose a cada momento y a cada contexto, permite que los individuos puedan tender al bien y a lo mejor. Uno de esos hábitos, por tanto, será la amistad, resultando incluso, según la interpretación de ciertos autores, el más importante, ya que de algún modo permite la actualización práctica de todas las demás virtudes. Es en mi relación con otros cuando yo puedo realmente mostrar a través de mis actos hasta qué punto soy o no virtuoso (SELLÉS, 2008).

A su vez, Aristóteles señala que existen tres tipos de amistad en función de cómo algo puede ser amado: porque es útil, porque es agradable o placentero y porque es bueno. A los dos primeros los llama accidentales, ya que "[...] en los que se quieren por interés, el cariño obedece al propio bien de ellos, y en los que se quieren por placer, a su propio gusto, y no por el modo de ser del amigo, sino porque es útil o agradable" (ARISTÓTELES, 2002, p. 1156a). Al segundo tipo lo denomina amistad perfecta, pues "[...] es la de los hombres buenos e iguales en virtud; porque [...] quieren el bien de sus amigos por causa de éstos, [...] [siendo] por su propia índole por lo que tienen esos sentimientos y no por accidente" (p. 1156b); o, lo que es igual, se trata de un tipo de amistad en el que se ama al amigo por ser quien es y por nada más, procurando siempre su bien. La amistad perfecta estaría presente, según Aristóteles, entre hombres de buen carácter, mientras que las accidentales lo son por semejanza o imitación a la perfecta, pudiendo darse en todo tipo de hombres (ARAIZA, 2005). Es importante señalar que las tres son clases de amistad porque existe una relación entre dos personas basada en un amor, aunque el origen se deba a motivos diferentes; a saber, en una de ellas se ama al amigo en sí y en las otras dos el beneficio propio que puede traer consigo dicha amistad (CALVO, 2003).

Sea de una clase u otra, la amistad vendrá definida para Aristóteles por la benevolencia recíproca, ya que, de los que "[...] desean el bien del otro, decimos que son benévolos si de la parte del otro no se produce el mismo sentimiento; [...] cuando la benevolencia es recíproca decimos que es amistad" (ARISTÓTELES, 2002, p. 1155b). De esta forma, "[...] la benevolencia se parece al sentimiento amistoso, pero no es ciertamente 
amistad; en efecto, la benevolencia se da incluso hacia personas que no conocemos y pasa inadvertida, y la amistad no" (p. 1166b). Así pues, uno puede desear y ejercer el bien para con cualquiera, pero no puede ser, sin embargo, amigo de cualquiera. Para que se produzca amistad no basta con que uno desee el bien del otro, sino que es imprescindible que dicho sentimiento sea mutuo y, además, manifiesto. A pesar de no ser sinónimo de amistad, continuará Aristóteles, “[...] parece, sin embargo, que la benevolencia es el principio de la amistad, [...] [surgiendo siempre aquélla] por alguna virtud y bondad, cuando una persona nos parece noble o viril o algo semejante" (p. 1167a); esto es, cuando nos parece buena en algún sentido ${ }^{3}$. Es entonces cuando le deseamos el bien, siendo benévolos con ella. Si, tras el trato, el sentimiento es mutuo, se habrá forjado una amistad. De lo contrario, podrá darse otro tipo de relación, pero en ningún caso esas personas podrán ser amigas.

Una vez que sabemos qué define y cómo se origina la amistad, que hemos distinguido varios tipos y que hemos dado con el más perfecto, ya sólo nos resta averiguar cómo podemos garantizar su ejercicio, dejando atrás los tipos de relación amistosa más imperfectos. Aristóteles tendrá una respuesta clara en este sentido. Según sostiene, "[...] las relaciones amistosas con nuestro prójimo y las notas por las que se definen las distintas clases de amistad parecen derivadas de los sentimientos que tenemos respecto de nosotros mismos" (ARISTÓTELES, 2002, p. 1166a). Es decir, que en función de cómo actuemos y nos comportemos con relación a nosotros mismos, así actuaremos y nos comportaremos con los demás. Continuará Aristóteles su argumentación sosteniendo más adelante que "[...] el hombre bueno debe ser amante de sí mismo" (p. 1169a). Ahora bien, no en el sentido de "[...] aquellos que se asignan una parte mayor de lo que les corresponde en riqueza, honores y placeres" (p. 1168b) y tienen esto como único objetivo, pues esto sólo conduciría a experimentar las clases más imperfectas de amistad, sino en el sentido de quien "[...] se apropia, en efecto, los bienes más nobles y más altos, y satisface a la parte más principal de sí mismo" (p. 1168b), que para Aristóteles será la razón.

Así pues, según Aristóteles, el individuo más proclive a la amistad perfecta será, por tanto, aquel que se rija por su razón, que controle sus pasiones, que piense de manera inteligente reflexionando siempre antes de actuar, siendo prudente, no precipitándose y siguiendo aquellas líneas de acción que puedan considerarse claramente más nobles.

Por darse en el hombre de bien todas estas condiciones -concluirá- y por tener para con su amigo las mismas disposiciones que para consigo mismo (puesto que el amigo es otro yo), también parece consistir la amistad en algo de esto, y ser amigos aquellos en quienes se dan esas condiciones. (ARISTÓTELES, 2002, p. 1165b).

Es decir, que son aquellos quienes han aprendido a pensar por sí mismos a detectar el bien para sí, los que en mayor medida podrán detectarlo con respecto a los demás y quienes, por tanto, podrán más probablemente hallar la perfección en su relación de

3- El sentido puede variar, siendo esto lo que hace que la amistad sea de una clase o de otra. Uno puede considerar a la persona con quien quisiera forjar una amistad buena en sí misma, o buena porque puede ayudarle a obtener algún tipo de bien o de placer personal. Así pues, aquí nos referimos a la benevolencia como origen de la amistad y no a las razones de dicha benevolencia, que nos llevarían a distinguir entre diferentes tipos de amistad. 
amistad. El bien, desde una perspectiva aristotélica, es el que es y no hay más, por eso los amigos que por causa de ellos mismos lo son, tienden hacia cierta unanimidad que únicamente “[...] se da en los buenos, pues éstos están de acuerdo consigo mismos y entre sí, y teniendo, por así decirlo, un mismo deseo, [...] quieren a la vez lo justo y lo conveniente, y a esto aspiran en común" (p. 1167b).

Es sin duda esta unanimidad la que llevó a Aristóteles a investigar la amistad, ya que sabía que esta relación, llevada a la perfección, podría garantizar una vida política en comunidad armoniosa y cercana a la paz (ROCHA, 2006). Quizá, desde un punto de vista moderno, nos sea difícil entender lo que significaba la amistad pública, pues hoy, por determinadas razones que apuntaremos en el siguiente apartado, tendemos a concebirla como una relación reducida al ámbito de lo privado. No obstante, veremos hasta qué punto puede ser interesante, aunque sólo sea atendiendo a la esfera privada, pensar la amistad, tal y como lo hizo Aristóteles, desde una perspectiva moral. Atendiendo a sus palabras, “[...] la vida consiste principalmente en sentir y pensar” (ARISTÓTELES 2002, p. 1170a) y si bien lo primero es importante, lo segundo resultará esencial si queremos que nuestros sentimientos vayan siempre teñidos de moral.

\section{Jóvenes creciendo en un mundo hiperconectado: cómo se construyen y qué caracteriza a las relaciones de amistad en el siglo XXI}

Era la capacidad de ver al otro como igual a uno mismo a pesar de las diferencias, gracias al trabajo reflexivo y racional sobre sí mismo, así como al conocimiento de una tradición y una historia compartida que, con el paso de los años y las generaciones, se iba cada vez afianzando más, lo que hacía no peligrar una idea de humanidad sustentada en la comunidad (ARENDT, 1993). No obstante, esto cambiaría con la llegada de la Modernidad, cuando todos los grandes referentes culturales se pondrian en cuestión, quedando el yo, en tanto que individuo despojado de toda relación, como lo único en lo que realmente se podía confiar. El sujeto humano pasaba a hacerse a sí mismo, era proyecto, de modo que tenía ante él abiertas todas las posibilidades, y todo ello independientemente de los demás ${ }^{4}$. Esto hizo que triunfase un sistema político y socioeconómico aún vigente basado fundamentalmente en lo material, el cual está más preocupado por satisfacer intereses particulares que por crear una comunidad plural que realmente se sienta como tal. Lo espiritual, que un día fue público, pasó a formar parte del ámbito privado y, con el tiempo, ni siquiera eso, surgiendo un tipo de ser humano incapaz de pensar, al mismo tiempo que capaz de dejarse conducir a cualquier parte siempre y cuando no peligrase su nivel de vida material (ORTEGA Y GASSET, 1997).

De esta forma, los inicios de la Modernidad y la veda que entonces se abrió condujeron, a finales del siglo XX, a lo que Lipovetsky denominó la era del vacío, materializada en una sociedad que se caracterizaba por "[...] no [tener] ídolo ni tabú, ni tan sólo una imagen gloriosa de sí misma, ningún proyecto histórico movilizador; estamos -concluía el autor- ya regidos por el vacío, un vacío que no comporta, sin

4- Para un estudio pormenorizado del proceso de construcción de la identidad moderna véase Taylor (2003). 
embargo, ni tragedia ni apocalipsis" (2002, p. 10), sino simplemente monotonía y, en muchos casos, soledad. El hecho de que los intereses personales rijan el funcionamiento de una sociedad cuyos miembros, aparte de un marcado instinto de supervivencia, poco comparten, hace que no sea difícil experimentar la soledad, pues las amistades vienen en muchos casos marcadas por elementos cercanos al tipo de amistad que Aristóteles definió como imperfecta y que aboca inevitablemente a la soledad cuando uno persigue algo más profundo y espiritual. Es por ello que no es de extrañar que la soledad se haya convertido en una epidemia de nuestra sociedad. En cuanto uno no encaja con la inercia del momento o necesita algo más que la mera satisfacción material, experimenta un vacío, tipificado por los psicólogos como soledad y que ha llegado a tipificarse como enfermedad mental (HEINRICH; GULLONE, 2006).

Este problema es el que las tecnologías de la información y la comunicación (TIC) vendrían a solucionar. Con el surgimiento del ciberespacio y de aplicaciones y herramientas que facilitan la comunicación a nivel global, se hace complicado experimentar la soledad, pues sea lo que sea aquello que nos ocurra, no resulta difícil dar con alguien en quien nos podamos apoyar. Encontramos, a este respecto, diferentes estudios que demuestran las ventajas que para las relaciones de amistad ha tenido la popularización de estas tecnologías. Así, por ejemplo, se ha demostrado que las TIC, y sobre todo las redes sociales, sirven para aumentar el grupo de amigos, así como para fortalecer vínculos previamente creados, suponiendo un espacio de socialización más para quien nunca tuvo problemas para interaccionar con los demás y una oportunidad para aquellos que por una razón $u$ otra tienen dificultades para formar parte de una comunidad (VIDALES; SÁBADA, 2017). El ciberespacio es, por tanto, un lugar donde todo el mundo puede encontrar su lugar para crear, ampliar y afianzar lazos de amistad. Esto ha hecho que, hoy en día, estando al alcance de cualquier bolsillo, tanto en sentido literal como figurado ${ }^{5}$, se haya convertido, tanto en adultos como en adolescentes, en un medio esencial para relacionarse en comunidad; una comunidad con muchos frentes que podría ser tildada de aumentada (REIG, 2012), debido a que atañe a todos los ámbitos de nuestra vida a la vez, viéndose mezclados en nuestro smartphone por muchas carpetas y secciones que incluyamos para separarlos.

Esta mezcla hace que hoy asistamos al surgimiento de un nuevo tipo de intimidad y de relación de los individuos con el mundo y con los demás. Se trata de una intimidad no pública ni privada, sino una mezcla de ambas, acorde con las características de nuestro mundo hiperconectado actual (XAVIER; NEVES, 2014); y es que, por mucho que algunas de las plataformas que usemos hagan pública parte de nuestra vida privada, siempre hay pequeñas estrategias para que lo que allí aparezca refleje la realidad a medias. Por un lado, la posibilidad de editar antes de publicar hace que podamos publicitar nuestras opiniones $\mathrm{y}$ vivencias atendiendo más a quienes nos van a observar, que a lo que realmente ha pasado o pensamos (MALLET, 2016). Por otro lado, el uso de códigos, metáforas o signos ocultos en nuestra publicación permite que sólo algunos comprendan plenamente lo allí

5- A pesar de que la brecha digital sigue existiendo y de que muchas personas no disponen aún de acceso a internet ni de dispositivos para hacerlo, año tras año no deja de reducirse. Saber manejar las TIC se ha convertido en imperativo para lograr la igualdad en nuestro mundo globalizado, de modo que la reducción de esta brecha se ha convertido para la Organización de las Naciones Unidas en asunto prioritario. A este respecto, véase Cañón, Grande y Cantón (2016). 
publicado, de modo que lo que podríamos denominar intimidad pública se mezcla con la privada, y de alguna manera la oculta al mismo tiempo que aparentemente la visibiliza (FARCI et al., 2016).

Ahora bien, todo aquello que de positivo podría tener esta intimidad ni pública ni privada, se ve ensombrecido si atendemos de manera detallada al contexto en el que es producida. Es un hecho que vivimos en un mundo hiperconectado que constantemente reclama nuestra atención. Se nos exige ser buenos ciudadanos, buenos profesionales, buenos amigos y familiares, siempre y en todo momento. Esto implica estar siempre disponibles para quien, desde los múltiples ámbitos de nuestra vida, reclame nuestra atención. El hecho de disponer de medios de conexión instantánea hace que poco a poco perdamos la capacidad de esperar, ya que sabemos que existe la posibilidad de que nos respondan ya. A su vez, las noticias vuelan y si queremos expresar nuestro parecer al respecto, debe ser al momento, porque unos minutos después ya a nadie le importará. Es por esta razón por la que intentamos abarcar todo y es tanto lo que hay que abarcar, que terminamos por no llegar. Tal y como afirma Corea, "[...] nuestras prácticas cotidianas están saturadas de estímulos, entonces, la desatención o la desconexión son los modos de relación con esas prácticas o esos discursos sobresaturados” (2004, p. 50).

Dada esta situación, no es de extrañar que, a pesar de tantas posibilidades para contactar, el sentimiento de soledad y de abandono siga siendo una constante (TURKLE, 2011); y es que, la amistad verdadera necesita tiempo de atención, una atención real que debe alejarse de cualquier distracción. Ahora bien, es difícil no distraerse en cualquier situación si disponemos de un dispositivo que siempre nos acompaña dándonos aviso constante de todos los frentes que tenemos abiertos. Vivimos incesantemente interrumpidos, de tal forma que cuando nos encontramos con un amigo, cara a cara, estamos presentes, pero al mismo tiempo ausentes (TURKLE, 2015). A esto hay que añadir que, poco a poco, los jóvenes están empezando a preferir la comunicación digital a la física, pues, como ya apuntábamos más arriba, a distancia podemos editar aquello que vamos a decir, lo cual hace más difícil que metamos la pata, sobre todo cuando tenemos una reputación que mantener. La red nos permite experimentar con nuestra identidad, crearnos un yo a gusto de aquellos a quienes queremos gustar, de manera que el yo que allí aparece es más posible -lo que nos gustaría ser- que real -lo que realmente somos- (FORBES, 2017). Vivimos, por tanto, con la presión constante de cumplir con unas exigencias externas que en el fondo no siempre podemos cumplir y esto hace que la honestidad, tradicionalmente esencial en toda amistad, deje de ser tan importante.

Vamos de un lado a otro, rápidos, veloces, sin mucho tiempo para pensar, pero con una idea clara: tenemos que destacar y tenemos que gustar. Las redes se han convertido en escaparates de nuestra vida, que deben pujar por llamar la atención (SIBILIA; DOG0, 2011). Sostiene a este respecto Byung-Chul Han que "[...] hoy, la economía de la atención ha sustituido tanto a la poética de la atención como a la ética de la atención, extinguiéndolas. [Dicha economía] traiciona lo distinto" (2017, p. 103), y no hay nada más distinto que un amigo verdadero, que es igual a mí a pesar de sus muchas diferencias, las cuales me complementan. Hoy en día huimos de la diferencia; hay varios caminos, pero todos marcados. Cada individuo, en función de sus circunstancias, escoge uno, sin embargo, 
una vez escogido, todo se torna igual sin dar lugar a la menor distinción. Una atención economizada, no da para más, es superficial y carece de toda profundidad. Una atención ético-poética, en cambio, busca y atiende a la diferencia, y no solo eso, sino que lo hace con tal minuciosidad que la comprende.

La atención sincera y sin distracciones, es base de la ética y fundamento del respeto (ESQUIROL, 2006) y esto se hace difícil cuando hay tanto a lo que atender que no nos llega el tiempo. Así pues, se nos hace fácil hacer amigos, al igual que deshacerlos. La amistad, al igual que el amor, que siempre fue un concepto sólido, ahora es líquido (BAUMAN, 2003), cuando los seres humanos necesitamos tener bases sólidas en las que apoyarnos para no caernos. Pasar al siguiente, como si de un catálogo se tratase, ha devenido costumbre entre los más jóvenes, y, ya lo veíamos con Aristóteles, con la amistad, cuando ésta es perfecta, no se comercia. Hoy las nuevas generaciones están aprendiendo que los amigos pueden contarse por cientos, así como estrategias que sirven para llamar su atención y que la lista no decrezca. La capacidad de comunicación y las habilidades sociales se miden por el éxito en las redes sociales, es decir, por el número de likes con los que uno cuenta o por los seguidores que tiene. No se trata tanto de hacer amigos como de devenir visible, admirable, envidiable por todas y por todos, protagonista de un mundo donde quién uno es se mide por la apariencia con la que se presente ante los demás (SIBILIA, 2008). En nuestro mundo hiperconectado no cabe duda de que se da cierta individualización, ya que uno busca ser alguien único y distinto ante y frente a los demás. No obstante, lo que no se da es la individuación. Siguiendo a Stiegler,

[...] la individualización, [...] en tanto que opuesta a la individuación, [...] no interioriza, así como la disciplina de esta tecnicidad no contribuye a la construcción del yo. La individualización conduce a la automatización, privando a los individuos del conocimiento per se [...]. (2010, p. 127).

ya que les hace actuar, comportarse y buscar modos únicos de ser que, en realidad, no los llevan sino a reproducirse como copias de lo que viene marcado por la inercia determinado contexto social. Así pues, pensando todo el tiempo en agradar, acaban por olvidarse de sí mismos y de los demás, en tanto que personas que deberían constituir algo más que sujetos observantes y a los que observar. La inercia del contexto ha hecho que nuestros jóvenes conozcan única y exclusivamente modos de amistad accidentales, que Aristóteles denominaría imperfectos, y que rebajan en dignidad humana las relaciones de amistad. No es de extrañar, por tanto, que continuamente confundan contacto y amistad (BOHÓRQUEZ; RODRÍGUEZ-CÁRDENAS, 2014), pues sólo experimentan relaciones no profundas, sino banales (CONDELLA, 2010).

\section{Educación y formación en la comprensión del valor de las relaciones de amistad}

Aristóteles no específica cómo es la amistad entre la gente joven, aunque sí aporta algunas consideraciones relevantes. De esta forma, sostiene que los jóvenes tienden por naturaleza a un tipo de amistad imperfecta, pues en su caso "[...] parece tener por causa 
el placer; éstos viven, en efecto, de acuerdo con el sentimiento, y persiguen sobre todo lo que les es agradable y lo presente; pero, al avanzar en edad, -concluye- las cosas que les resultan agradables son también otras" (ARISTÓTELES, 2002, p. 1156a), siendo éstas las que les terminan conduciendo a experimentar la modalidad más perfecta de amistad. Será la educación y formación del carácter lo que les haga llegar hasta ahí, ya que “[...] el cariño tiene la apariencia de un sentimiento, y la amistad la de una disposición de carácter, pues el cariño no se da menos respecto a las cosas inanimadas, pero la amistad recíproca implica elección, y la elección implica una disposición” (p. 1157b), la cual deberá ser educada a través de un trabajo que, ya lo vimos en el primer apartado, no será meramente externo para Aristóteles, sino fundamentalmente de individuación o interno. Se trata, por lo tanto, de un trabajo detenido sobre sí mismo que abrirá al individuo al bien y a la moral, de tal forma que posteriormente pueda buscarlo en otros e irradiarlo hacia el exterior. Es por ello por lo que será imposible contar con muchos amigos en el sentido de la amistad perfecta, pues "[...] es preciso adquirir experiencia y llegar a una intimidad" (p. 1158a) que a la fuerza se fragua lenta.

El hecho de que en la Modernidad la amistad se viese reducida al ámbito privado hizo que fuese fácilmente confundida con el cariño. De esta forma, fue tratada como un sentimiento, un afecto o una pasión. Esta idea ha sido asumida en la actualidad, ya que la amistad es concebida como relación afectiva de ayuda o apoyo basada en la colaboración de unos con otros (LUQUE; LUQUE, 2015). La sociedad del siglo XXI entiende que dos amigos que se quieren recíprocamente comparten un bien pragmático que nada tiene que ver con cómo ellos sean de manera esencial. En este sentido, Daguerre (2010) afirma que ser amigo de otro no radica tanto en buscar el bien del otro, sino en darle lo que espera de la relación de amistad, que suele reducirse a comentarios, likes y entretenimiento constante por la vía virtual. Las relaciones se sustentan, por tanto, en el contacto que permite estar al tanto de nuestro día a día, de compartir y comentar diferentes realidades que nos puedan interesar, pero sin revelarnos del todo, sin dejar a los otros pasar esa franja que permite dar cuenta de quién uno realmente es sin trampa ni cartón, con virtudes, pero también con múltiples defectos. Nuestra atención es constantemente reclamada, se nos enseña a mostrarnos, a compartir imágenes y sentimientos, sobre todo si tienen que ver con la alegría o el bienestar, pero también se nos transmite que el tiempo es escaso, que hay mucho a lo que atender y que no podemos ni debemos abusar del tiempo de los demás. Ahora bien, cuando uno realmente se encuentra mal, necesita tiempo de acompañamiento, de comprensión y consideración, lo cual va más allá del emoticono o el simple comentario al uso que suponen las relaciones basadas en el contacto. Es por ello que, o bien intentamos reclamar ese tiempo y acabamos encontrándonos solos (LEE; K0, 2018), o bien ocultamos nuestros verdaderos sentimientos, pues tenemos miedo de que los demás no puedan darnos aquella profundidad en las relaciones que en determinadas ocasiones resultan humanas y necesarias ${ }^{6}$.

\footnotetext{
6- En casos extremos, esto ha conducido a la creación de comunidades de gente que se dicen amigos, pero cuya relación se reduce única y exclusivamente a compartir la pasión por mundos de fantasía y de ficción, sin profundizar en nada más personal. Es el caso del fenómeno otaku, surgido en Japón, pero cada vez más extendido en Occidente. Se trata de personas que establecen lazos de amistad a partir de sus comics manga preferidos, pero que no saben si estas personas tienen padres, hermanos, pareja o ni siquiera a qué se dedican o dónde y con quién viven. Para más información, véase Satomi (2007).
} 
A su vez, hemos de añadir a esto que la concepción de la relación de amistad de modo pragmático, que Aristóteles definiría como accidental o imperfecta, y a la cual nos conduce de manera directa nuestro contexto actual, ha tenido sus consecuencias en el ámbito de la educación, pues, siguiendo dicha concepción, la educación en la amistad se ha enfocado, más allá de toda profundidad, en el logro de destrezas a la hora de socializar (GIRÓ, 2011). No obstante, tal y como hemos podido observar analizando el concepto de amistad a partir de Aristóteles, no cabe confundir ser amigo de otro de manera perfecta con aprender a socializar, ya que esta competencia no tiene por qué venir acompañada de componente moral alguno, así como tampoco de un conocimiento íntimo y personal de la persona con la que uno se vaya a relacionar. Tal y como sostiene Prieto, "[...] la consideración del mundo y de los otros apela a un carácter ético, ineludible para la educación, al que en las teorías de la Inteligencia Emocional y la Psicología Positiva, no se otorga el papel central que ha de desempeñar en la educación" (2018, p. 305). No basta, por tanto, con aprender a detectar y gestionar nuestras emociones, ni con saber cómo, cuándo y de qué manera es más idóneo relacionarnos con los demás. Si queremos que nuestro mundo siga siendo humano, es necesario escapar, aunque sólo sea de manera temporal, de aquello que nos dicta el contexto y recuperar ciertas maneras de educar a nuestros hijos en cómo relacionarse consigo mismos y con los demás que, más allá de hacerlos diestros y hábiles a la hora de socializar, induzca en ellos cierta perspectiva moral.

Es en este sentido en el que reclamamos aquí la importancia educativa de recuperar el concepto aristotélico de amistad perfecta, pues el hecho de experimentarla posiblemente sea una de las experiencias morales más completas (PAHL, 2003). Ahora bien, la amistad perfecta, a diferencia de las imperfectas, no es algo que pueda transmitirse a través de fórmulas y estrategias, ya que de ningún modo puede definirse con base a destrezas. Lo único que podemos hacer, desde un punto de vista educativo, es establecer las condiciones de posibilidad que posibiliten que aparezca; unas condiciones que tendrán que ver con la formación del propio pensamiento el crítico, el cual no podrá ser ciertamente desarrollado sino de manera indirecta (STANDISH; THOILLIEZ, 2018).

Tal y como apuntábamos a partir de Aristóteles, para llegar a establecer con otra persona un lazo de amistad perfecta, es necesario realizar primero un trabajo individual, lo cual requiere tiempos y espacios de diálogo con uno mismo, a solas, pero no en soledad, pues no hay abandono cuando uno consigue estar consigo mismo de verdad. Es de esta forma como los seres humanos, a lo largo de la historia, se han desarrollado en tanto que sujetos morales (ARENDT, 2007). Esto pasa porque, desde pequeños, enseñamos a los niños la importancia de reflexionar por sí mismos, de ahondar en su interior haciéndolo cada vez más grande. No estaba equivocado Bachelard cuando afirmaba que "[...] se daría al niño una vida profunda otorgándole un lugar de soledad, un rincón” (2006, p. 129), pues únicamente a solas es posible aprender a pensar. Actividades como la lectura individual, por placer y silenciosa (LARROSA, 1996), la escritura de los propios pensamientos, sentimientos o apreciaciones, aunque no sea en un diario (CARDOSO; CARNEIR0, 2011), el estudio desinteresado (RECHIA; CUBAS, 2019), o todas aquellas actividades que consisten en la meditación, la visualización o la imaginación individual (GALANAKI, 2005), 
ayudarán a configurar un yo que, creándose una auténtica personalidad no dependiente de las modas ni del contexto, buscará lo mismo en sus relaciones con los demás ${ }^{7}$.

Estas actividades garantizan, por tanto, la formación de personas que habiéndose desarrollado a sí mismas, como sujetos individuados, autónomos y con capacidad moral, sean capaces de amar desinteresadamente. Nuestro mundo hiperconectado reclama este tipo de educación de la amistad, pues la mera vivencia de amistades imperfectas, así como la falta de tiempos y espacios para reflexionar y crearse una auténtica personalidad moral, puede conducirnos, si no lo está haciendo ya, a vínculos de claro carácter inmoral ${ }^{8}$.

\section{Conclusión}

Empezamos este trabajo haciendo referencia a una novela distópica que relataba la soledad y falta de humanidad a la que eran condenados los habitantes de un mundo donde todo vínculo venía tecnológicamente mediado. Hoy, habitando un mundo en muchos aspectos similar, sabemos que no todo es negativo y que son muchas las ventajas de dicha mediación. Estamos más y mejor informados, así como tenemos muchos más medios para relacionarnos con los demás, fortaleciendo lazos que, antes de existir el ciberespacio, la distancia y el reducido tiempo habrían hecho, o bien que nunca se creasen, o que terminasen por desaparecer. No obstante, también es cierto que existen determinados peligros y que la dinámica de rapidez, instantaneidad y superficialidad en los contactos a la que nos condena el estado de cosas actual, nos ha llevado a olvidar la pureza de ciertas relaciones que siempre otorgaron dignidad a la humanidad. Éste es el caso de la denominada por Aristóteles amistad perfecta, un tipo de vínculo que apuntaba al amor desinteresado, recíproco y que venía sustentado en una idea de bien previamente lograda gracias a un proceso de introspección reflexiva.

Cierto es, tal y como sostiene Kristjánsson (2019), que las relaciones de amistad siempre fueron inestables y bastante frágiles, de manera que pensar, tal como lo hizo Aristóteles, que el trabajo sobre uno mismo y el amor desinteresado por el otro darán lugar siempre y de manera automática a relaciones pacíficas y eternamente duraderas, es tener una visión demasiado positiva, idealizada y utópica del espíritu humano. Ahora bien, consideramos aquí, siguiendo a Ruyter (2006), que en educación es esencial perseguir ideales, a pesar de ser conscientes de que muy probablemente no serán plenamente alcanzables. El concepto de amistad perfecta de Aristóteles encierra un ideal que, tal y como hemos demostrado, vale la pena ser perseguido, pues las relaciones humanas merecen estar, en la medida de lo posible, teñidas de moral, lo cual se hace difícil con el modo superficial que tenemos hoy en día de educarnos en la amistad.

\footnotetext{
7- Si bien estas recomendaciones, sucintamente mencionadas, podrían interpretarse en tanto que genéricas y quizá alejadas de la práctica educativa real, existen diversos estudios empíricos donde se muestra claramente que el tipo de relación con los otros que surge a partir del trabajo previo sobre uno mismo, nada tiene que ver con el que se fragua apenas siguiendo ciertas fórmulas de interacción social tradicionalmente aceptadas. A este respecto, véanse Silveira y Ferreira (2013) y Fonseca, Dias Medeiros y Cavalcante (2016).

8- Podríamos mencionar a este respecto el ciberacoso, el grooming y otra serie de relaciones violentas vivenciada por menores en la red. A este respecto, véase Pérez, Burguera y Larrañaga (2013).
} 
Actualmente, la falta de tiempo a la que nos condena un permanente estado de hiperconexión, así como la reducción de la amistad a un sentimiento de cariño, separado de toda moral, ha hecho que las relaciones de amistad hayan perdido en dignidad. Es por ello que es importante reclamar la necesidad educativa de implementar, tanto en la familia como en la escuela, un proceso de recuperación conceptual. Esto pasa por no reducir toda actividad y formación de los niños a tareas que conlleven interacción y colaboración, sino por conservar y fomentar ciertas actividades que requieren ser realizadas en soledad. Hagamos a nuestros jóvenes aptos para entender y experimentar la amistad perfecta. Sólo así evitaremos que la Máquina tome el control como en la novela de Forster. El control siempre debe ser humano y, si algo caracteriza a la humanidad, es la moral.

\section{Referencias}

ARAIZA, Jesús. Sobre la amistad según la teoría ética de Aristóteles. Nova Tellus: Anuario del Centro de Estudios Clásicos, México, DF, v. 23, n. 2, p. 125-159, 2005.

ARENDT, Hannah. Algunas cuestiones de filosofía moral. In: ARENDT, Hannah (Comp.). Responsabilidad y juicio. Barcelona: Paidós, 2007. p. 75-150.

ARENDT, Hannah. La condición humana. Barcelona: Paidós, 1993.

ARISTÓTELES. Ética a Nicómaco. Madrid: Centro de Estudios Constitucionales, 2002.

ARISTÓTELES. Política. Madrid: Centro de Estudios Constitucionales, 1983.

BACHELARD, Gaston. La tierra y las ensoñaciones del reposo. México, DF: Fondo de Cultura Económica, 2006.

BÁRCENA, Fernando. Hannah Arendt: una filosofía de la natalidad. Barcelona: Herder, 2006.

BARRI0, José María. Cómo formar la segunda naturaleza: notas antropológicas acerca de la educación de los hábitos. Estudios Sobre Educación, Pamplona, n. 13, p. 7-23, 2007.

BAUMAN, Zygmunt. Amor líquido: acerca de la fragilidad de los vínculos humanos. México, DF: Fondo de Cultura Económica, 2003.

BERTI, Enrico. A relação entre as formas de amizade segundo Aristóteles. Analytica. Revista de Filosofia, Rio de Janeiro, v. 6, n. 1, p. 23-44, 2001.

BOHÓRQUEZ, Catalina; RODRÍGUEZ-CÁRDENAS, Diego Efrén. Percepción de amistad en adolescentes: el papel de las redes sociales. Revista Colombiana de Psicología, Bogotá, v. 23, n. 2, p. 325-338, 2014.

CALVO, Tomás Mariano. La concepción aristotélica de la amistad. Bitarte, Donostia, n. 30, p. 29-40, 2003. 
CAÑÓN, Ruth; GRANDE, Mario; CANTÓN, Isabel. Brecha digital: impacto en el desarrollo social y personal. Factores asociados. Tendencias Pedagógicas, Madrid, n. 28, p. 29-40, 2016.

CARDOSO, Lígia; CARNEIRO, Maria de Fátima. A escrita como dispositivo de formação em educação. Cadernos de Educação, Pelotas, n. 39, p. 175-192, 2011.

CONDELLA, Craig. Why can't We be virtual friends? In: WITTKOWER, Dylan E. (Ed.). Facebook and philosophy: what's on your mind? Chicago: Open Court, 2010. p. 111-121.

COREA, Cristina. Pedagogía y comunicación en la era del aburrimiento. In: COREA, Cristina; LEWKPWICZ, Ignacio (Comp.). Pedagogía del aburrido: escuelas destituidas, familias perplejas. Buenos Aires: Paidós, 2004. p. 41-70.

DAGUERRE, Martín. Sobre el valor de la amistad y su conflicto potencial con la moral: una revisión del debate contemporáneo. Diánoia, México, DF, v. 55, n. 64, p. 47-69, 2010.

ESQUIROL, Josep María. El respeto o la mirada atenta: una ética para la hora de la ciencia y la tecnología. Barcelona: Gedisa, 2006.

FARCI, Manolo et al. Networked intimacy: intimacy and friendship among Italian facebook users. Information, Comunication \& Society, London, v. 20, n. 5, p. 1-18, 2016.

FONSECA, Thaisa; DIAS MEDEIROS, Cássia; CAVALCANTE, Ana Célia. Habilidades sociais de amizade e civilidade no contexto escolar. Estudos Interdisciplinares em Psicologia, Londrina, v. 7, n. 2, p. 147-156, 2016.

FORBES, Cameron. Authentic friendship in the age of social media. Pacifica, Melbourne, v. 29, n. 2, p. 161-174, 2017.

FORSTER, Edward Morgan. The machine stops. London: Penguin Group, 2011.

GALANAKI, Evangelia. Solitude in school: a neglected facet for children's development and education. Childhood Education, London, v. 81, n. 3, p. 128-132, 2005.

GIRÓ, Joaquín. Las amistades y el ocio de los adolescentes, hijos de la inmigración. Papers: Revista de Sociología, Barcelona, v. 96, n. 1, p. 77-95, 2011.

HAN, Byung-Chul. La expulsión de lo distinto. Barcelona: Herder, 2017.

HEINRICH, LiesI M.; GULLONE, Eleonora. The clinical significance of loneliness: a literature review. Clinical Psychology Review, Amsterdam, v. 26, n. 6, p. 695-718, 2006.

KRISTJÁNSSON, Kristján. Ten un-Aristotelian reasons for the instability of Aristotelian character friendships. Journal for the Theory of Social Behaviour, New York, v. 49, n. 1, p. 40-58, 2019.

LARROSA, Jorge. La experiencia de la lectura: estudios sobre literatura y formación. Barcelona: Laertes, 1996. 
LEE, Yeeun; KO, Young-gun. Feeling lonely when not socially isolated: social isolation moderates the association between loneliness and daily social interaction. Journal of Social and Personal Relationships, Thousand Oaks, v. 35, n. 10, p. 1340-1355, 2018.

LIPOVETSKY, Gilles. La era del vacío. Barcelona: Anagrama, 2002.

LUQUE, Diego Jesús; LUQUE, María Jesús. Relaciones de amistad y solidaridad en el aula: un acercamiento psicoeducativo a la discapacidad en un marco inclusivo. Revista Mexicana de Investigación Educativa, México, DF, v. 20, n. 65, p. 369-392, 2015.

MALLET, Pascal. La amistad entre niños o adolescentes: una fuerza que ayuda a crecer. Madrid: Narcea, 2016.

ONG, Walter. Oralidad y escritura: tecnologías de la palabra. México, DF: Fondo de Cultura Económica, 1982.

ORTEGA, Francisco. Genealogias da amizade. São Paulo: lluminuras, 2002.

ORTEGA Y GASSET, José. La rebelión de las masas. Madrid: Alianza, 1997.

PAHL, Ray. Sobre la amistad. Madrid: Siglo XXI, 2003.

PÉREZ, Salvador; BURGUERA, Leyre.; LARRAÑAGA, Kepa Paul. Menores e internet. Pamplona: Thompson Reuters Aranzadi, 2013.

PRIETO, Miriam. La psicologización de la educación: implicaciones pedagógicas de la inteligencia emocional y la psicología positiva. Educación XX1, Madrid, v. 21, n. 1, p. 303-320, 2018.

RECHIA, Karen Christine; CUBAS, Caroline Jacques. Una skholé para profesores: el estudio como dimensión constitutiva del oficio de professor. Teoría de la Educación, Salamanca. v. 31, n. 2, p. 109-130, 2019.

REIG, Dolors. Socionomía: ¿Vas a perderte la revolución social? Barcelona: Deusto, 2012.

ROCHA, Zeferino. 0 amigo, um outro si mesmo: a Philia na metafísica de Platão e na ética de Aristóteles. Psychê, São Paulo, v. 10, n. 17, p. 65-86, 2006.

RUYTER, Doret. Whose utopia? Which ideals? The importance of societal and personal ideals in education. In: PETERS, Michael; FREEMAN-MOIR, John (Ed.). Edutopias: new utopian thinking in education. Leiden: Brill, 2006. p. 163-174

SATOMI, Ishikawa. Seeking the self: individualism and popular culture in Japan. Berna: Peter Lang, 2007. SELLÉS, Juan Fernando. La educación de la amistad: una aproximación conceptual. Educación y Educadores, Chía, v. 11, n. 1, p. 145-166, 2008.

SIBILIA, Paula. La intimidad como espectáculo. Buenos Aires: Fondo de Cultura Económica, 2008. 
SIBILIA, Paula; DOGO, Lígia. Vitrines da intimidade na internet: imagens para guardar ou para mostrar? Estudos de Sociologia, Araraquara, v. 16, n. 30, p. 127-139, 2011.

SILVEIRA, Marília; FERREIRA, Ligia. Escritas de si, escritas do mundo: um olhar clínico em direção à escrita. Athenea Digital, Barcelona, v. 13, n. 3, p. 243-263, 2013.

STANDISH, Paul; THOILLIEZ, Bianca. El pensamiento crítico en crisis: una reconsideración pedagógica en tres movimientos. Teoría de la Educación, Salamanca, v. 30, n. 2, p. 7-22, 2018.

STIEGLER, Bernard. Taking care of youth and the generations. Standford: Standford University Press, 2010.

TAYLOR, Charles. Las fuentes del yo: la construcción de la identidad moderna. Barcelona: Paidós, 2003.

TURKLE, Sherry. Alone together: why we expect more from technology and less from each other. New York: Basic Books, 2011.

TURKLE, Sherry. Reclaiming conversation: the power of talk in a digital age. New York: Penguin Group, 2015.

VIDALES, María José; SÁBADA, Charo. Adolescentes conectados: la medición del impacto del móvil en las relaciones sociales desde el capital social. Comunicar, Huelva, n. 53, p. 19-28, 2017.

WALKER, David lan; CURREN, Randall; JONES, Chantel. Good friendships among children: a theoretical and empirical investigation. Journal of the Theory of Social Behaviour, Hoboken, v. 46, n. 3, p. 1-24, 2016.

XAVIER, Maria Rita; NEVES, Thiago. Por uma vida afetada - afetos, tecnologia e vínculos na contemporaneidade. Revista Eletrônica Inter-legere, Natal, n. 14, p. 1-17, 2014. Disponible en: <https:// periodicos.ufrn.br/interlegere/article/view/5293>. Acceso en: 2 dic. 2018.

ZAGAL, Héctor. Amistad y felicidad en Aristóteles: ¿Por qué necesitamos amigos? Barcelona: Ariel, 2014.

Recibido en: 12.012 .2018

Revisado en: 23.04.2019

Aprobado en: 21.05.2019

Alberto Sánchez-Rojo es profesor ayudante doctor del Departamento de Estudios Educativos de la Universidad Complutense de Madrid (España). Miembro del grupo de investigación en Antropología y Filosofía de la Educación y del grupo de investigación en Procesos, Espacios y Prácticas Educativas, investiga temas relacionados con la Teoría y la Filosofía de la Educación.

Josu Ahedo-Ruiz es profesor de la Universidad Internacional de La Rioja (España), con dieciséis años de experiencia educativa en diferentes centros de enseñanza. Director del grupo de investigación El quehacer educativo en acción, investiga temas sobre educación del carácter y educación en valores. 